\title{
Publisher Correction to: Influence of focus and deflection when comparing electron beam welds to laser welds at varying parameters in 304 SS
}

Joris E. Hochanadel ${ }^{1} \cdot$ Tate Patterson $^{1} \cdot$ John C. Lippold $^{1} \cdot$ Boyd Panton $^{1} \cdot$ Matthew Q. Johnson $^{2} \cdot$ David C. Tung $^{2}$

Published online: 27 February 2021

(C) International Institute of Welding 2021

Publisher Correction to: Welding in the World https://doi.org/10.1007/s40194-020-01046-3

Due to a mistake during production the publication of this article unfortunately contained a mistake. Figure 10 was not correct, please see the correct Fig. 10 below.

The original article has been corrected.

Publisher's note Springer Nature remains neutral with regard to jurisdictional claims in published maps and institutional affiliations.

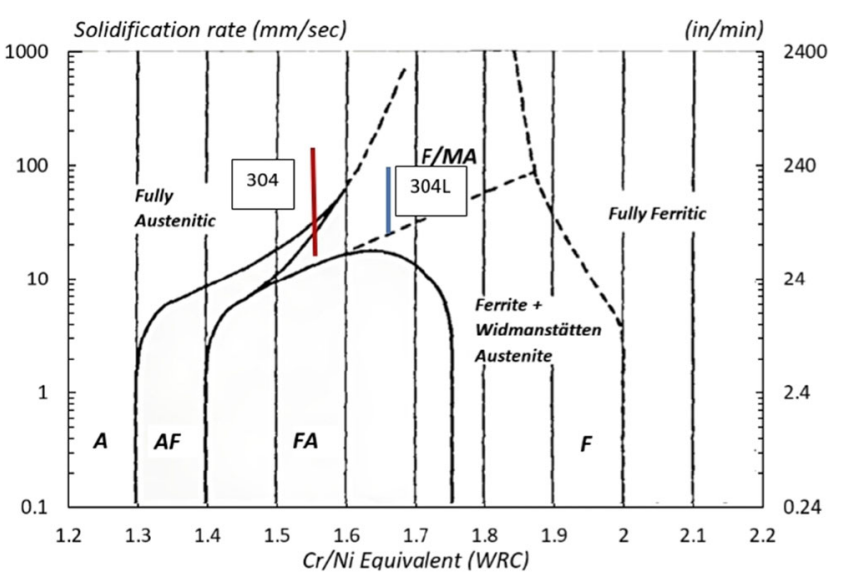

Fig. 10 Pulsed laser weld microstructural map, from [12]. The red line represents the range of solidification rates experienced by the 304 welds at the centerline. The blue line represents the range of solidification rates experienced by the $304 \mathrm{~L}$ welds at the centerline

The online version of the original article can be found at https://doi.org/ 10.1007/s40194-020-01046-3

Joris E. Hochanadel

hochanadel.4@buckeyemail.osu.edu

1 The Ohio State University, Columbus, OH, USA

2 Los Alamos National Laboratory, Los Alamos, NM, USA 